\title{
The Development of 'E-Layer' Android Mobile Application as Interactive Multimedia in Earth Layer Topics for Junior High School
}

\author{
Eksa Nursafira Sunarya ${ }^{1},{\text { Eka Cahya } \text { Prima }^{2} \text {, Yaya Wihardi }}^{3}$ \\ \{eksasafira@student.upi.edu ${ }^{1}$, ekacahyaprima@upi.edu ${ }^{2}$, yayawihardi@upi.edu ${ }^{3}$ \} \\ Department of Science Education, Faculty of Mathematics and Science Education, Universitas \\ Pendidikan Indonesia, Bandung, Indonesia ${ }^{1,2}$ \\ Department of Computer Science Education, Faculty of Mathematics and Science Education, \\ Universitas Pendidikan Indonesia, Bandung, Indonesia ${ }^{3}$
}

\begin{abstract}
Technological developments in this era are experiencing rapid progress. The android-based application is nowadays used to engage students' understanding of science learning. At this moment, we propose a new android learning application, named "ELayer", interactive multimedia for learning science. This application discusses physical material on the topic of the earth layer. This application is dynamically designed and equipped using Unity software with various supporting features, such as images, videos, sounds, and multi-language animation settings. The results showed that based on content expert evaluations, the average mobile learning score was $96 \%$, language evaluation based on experts was $82.50 \%$, and media design (IT) rated an average of $87.93 \%$ from the range $88.81 \%$. As well as based reviews from science teachers and junior high school students the percentage of mobile learning applications is $90.55 \%$ and 92.50 . This Android mobile application is very suitable for use as a learning application.
\end{abstract}

Keywords: E-Layer, Unity, Android Mobile Application, Interactive Multimedia

\section{Introduction}

In the 21 st century, features of different tools, different communication, various information, and different jobs. With this change, education must shift to combine computerbased electronic technology that integrates learning with this technology in the context of academic subjects [1]. Learning science using technology is a new challenge that must be faced by the educational sector today. However, we found some difficulties faced by teachers and students. The difficulty experienced by teachers in combining learning material using technology, in this case, is a learning application. Learning about the subject matter with technology is different from learning to teach subject matter with technology [1]. Some teachers have been taught to teach their subject matter with technology and as found by a survey by the Center for National Education Statistics, only 20\% of current state school teachers feel comfortable using technology in their teaching [2]. With the development of science and technology, the discomfort felt by the majority of teachers has found a bright spot for the problems with the technology of mobile applications.

A mobile application is a software or a program that runs on a mobile device whose job is to perform specific tasks for its users. Mobile apps are also one of the new things and a fast- 
growing segment of global information and communication technology [3]. Mobile applications easy, user-friendly, inexpensive, can be downloaded and run capably on most cellphones including cheap and entry-level cellphones [3]. Mobile applications are extensively used for a wide area of functions such as calling, messaging, browsing, chatting, social networking, communication, audio, video, games, etc. The mobile application is also a handheld device that can improve class dynamics because of its calculations and communication ability, which adds face-to-face interaction [4] and can support collaborative learning scenarios [5]. The mobile application also utilizes the brain in a smartphone that provides unique software applications to help deal with unlimited details in today's busy life. Most students having computers and wireless devices with almost 80 percent believing that the use of the Internet enhances their learning experience [6]. User requirements can be fulfilled in the current multimedia smartphone with the appropriate application. Applications that are appropriate for use by students should be combined with interactive multimedia.

Unique interactive multimedia for learning applications can help students not only to go further and allow students to choose their path through an app by pointing and clicking various menu items and buttons [7]. Mobile applications combined with interactive multimedia in this study will be focused on mobile applications about earth science. At present, mobile apps of earth science are emerging to be made. The material presented in this application is the layer of the earth. we viewed that a Novel Mobile Application suitable for junior high school students was required to be developed through this research. We will here propose the application entitled "E-layer." The app discusses the earth layer packaged as interactive multimedia. The E-layer has several features that are connected to the needs of students such as features that can help students understand the material contained therein, easy to understand videos, sound menus to help students with audio learning styles, and quizzes to measure students' abilities after using the application. This application also discusses physical material on the topic of the earth layer. This application will be constructed using Unity software. Unity is software that has the advantage to develop some applications for games or learning applications in two dimensions or three dimensions. To ensure that the application was appropriate to students, we will examine the quality by expert judgments, refining the apps, and testing the apps to students, respectively.

\section{Research Method}

The method used in this research is the developmental research method. The method can describe the development process of instrument and application in this research, and analyze the readability of the application later on. Developmental research facilitates the study of a new model, tools, and procedures. The method several stages where each stage involves reporting and analyzing data. The stages consist of sub-studies to analyze and define the instructional problem, to specify the content, to determine instrument reliability and validity, and to make a summative evaluation [8].

This research method is suitable and appropriate with the objectives of the research, which is to develop a collaborative problem-solving assessment tool on the earth layer topic because the study focuses on the development process of both instrument and application rather than merely gathering data.

The researcher created mobile learning in the form of an Android mobile application in the earth layer topic. Final paper supervisors then supervised the mobile learning application 
before the experts that expertize in content (Physics), language (English), and design (IT) assess it. After a sequence of suggestions and revisions until the final assessment, the mobile learning application was brought to students to be reviewed. The subject of this study were three experts in each aspect: science content, language, and design for mobile learning application validation. Those experts that already have a background based on what they expertise will assess these aspects. For mobile learning application impressions, Junior High School students will assess the media.

The location of this research is Private Secondary School "X" in Bandung. The school uses English as the communication and delivery language in the teaching-learning process. The curriculum that applies in this school is the National Curriculum which is Curriculum 2013. These curriculums are implemented for all grade of secondary school in both lower and higher secondary school. The population in this research will be the students of this Junior High School in Bogor. The sample will be 30 students from Junior High School in Bogor who will be chosen through purposive sampling.

The instruments are used to obtain or gain the data in this research. To measure the suitability of the android mobile learning application and how its design met students' actual necessity of comprehension in learning earth layer topic, the instruments that used are experts' judgment rubric and questionnaire for students and science teachers. The rubric used in this research is the Likert scale and ratings. The rubric was including two aspects: the techniques of making android mobile applications and characteristics of it. The features are the content, whether it is the earth layer topic, the language, and the design of mobile learning itself. The scale is 1 to 5 to determine if the points in the android mobile application were met the intention, goal, and expectations. The Likert scale and ratings are also used for students' and teachers' questionnaire. There was a 5-rating scale to determine whether the mobile learning application is compatible and suitable for Junior High School level or not. The elaborated scoring for the rating is in the form of a questionnaire.

\section{Result and Discussion}

\subsection{Design Stage}

The materials contained in android mobile learning application as interactive multimedia projects are earth layer topic which specified in Indonesian Curriculum 2013. In this android mobile application, the materials divide into some issues which are atmosphere and geosphere. The contents are deciphered in the teaching-learning process.

The flowchart is the illustration of story flow in the development process of android mobile applications as interactive multimedia. The flowchart is started from the initial process of using the android mobile app until the end by the user. The storyboard is the plan of multimedia that will be developed based on the flowchart to make the development stage easier. Figure 1 is the example of a storyboard from an android mobile application. The first page shows the main menu in which there is a language selection menu. After selecting the desired language option will go to the main menu again which will proceed to the help menu to find out the function of the available buttons. 

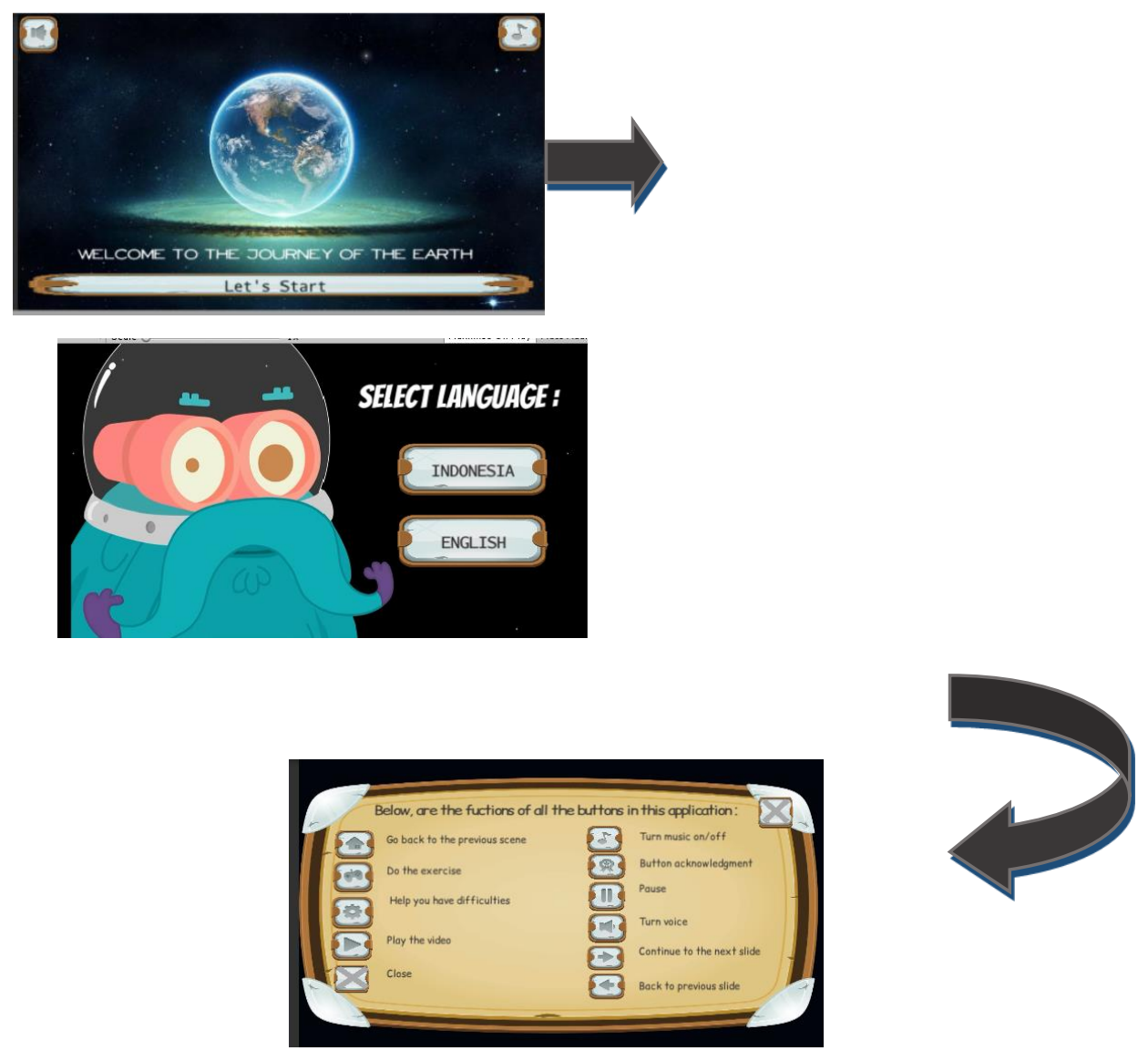

Fig. 1. The example of a storyboard scheme.

\subsection{Development Stage}

The interface was made based on the storyboard in the design stage. In this process, First, collect the user necessities and define the design conceptually, and then validate it. After that, the problems that arise should be fixed before it can be developed. Figure 2 shows the flow and display of a mobile learning application based on Arduino projects.

To check the apps' suitability, some experts are involved in judging the app as seen in Table 1. The experts are one expert in materials' content, two experts of language, and three experts in media (IT). Based on Table 2, the average percentage of judgments on content is $96 \%$ which can interpret as the "Very Good" category. The overall score of content judgments is concerned with the content presented in this android mobile application. The materials are already adequate for Junior High School students who study the earth layer based on the 2013 curriculum. The interest of contents that distinctly present from a usual textbook can boast students willing to consider quite difficult material differently. It can be seen by the percentage that given by experts both in accuracy and interest of contents that the contents 
offered in the application follow the curriculum and syllabus used in Junior High School that proper for their study.

Table 1. Experts' judgment result on content.

\begin{tabular}{|c|c|c|c|c|c|}
\hline No & Expert & Aspect & $\begin{array}{l}\text { Ideal } \\
\text { Score }\end{array}$ & $\begin{array}{l}\text { Result } \\
\text { Score }\end{array}$ & $\begin{array}{l}\text { Percentage } \\
(\%)\end{array}$ \\
\hline \multirow[t]{6}{*}{1} & $\begin{array}{l}\text { First } \\
\text { Expert }\end{array}$ & $\begin{array}{l}\text { Content Quality } \\
\text { (Veracity, accuracy, balanced presentation of } \\
\text { ideas, and appropriate level of detail) }\end{array}$ & 5 & 4 & 80 \\
\hline & & $\begin{array}{l}\text { Learning Goal Alignment } \\
\text { (Alignment among learning goals, activities, } \\
\text { assessments, and learner modeling) }\end{array}$ & 5 & 5 & 100 \\
\hline & & $\begin{array}{l}\text { Feedback and Adaption (Adaptive content or } \\
\text { feedback is driven by differential learner input } \\
\text { or learner modeling) }\end{array}$ & 5 & 5 & 100 \\
\hline & & $\begin{array}{l}\text { Motivation (Ability to motivate and interest an } \\
\text { identified population of learners) }\end{array}$ & 5 & 5 & 100 \\
\hline & & $\begin{array}{l}\text { Presentation Design (Design of visual and } \\
\text { auditory information for enhanced learning and } \\
\text { efficient mental processing) }\end{array}$ & 5 & 5 & 100 \\
\hline & & Average Score & & & $96 \%$ \\
\hline
\end{tabular}
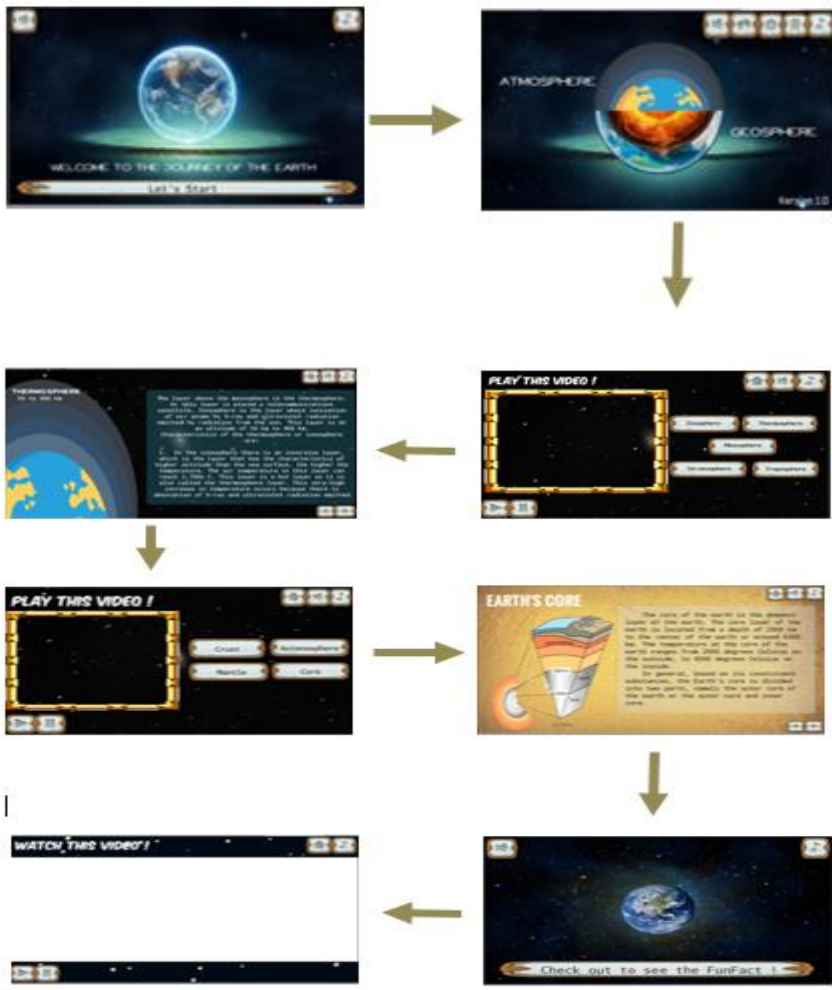

Fig. 2. The interface of android mobile application. 


\subsection{Implementation Stage}

Based on the result in Table 2. about the comparison result of each aspect based on science teachers' and the student responds, there are some aspects categorized as "Very Good" scale that has percentage range from $76 \%-100 \%$. The issues are mobile connectivity with $86.67 \%$, projects with $93.33 \%$, a quiz with $86.67 \%$, and personalized learning experience with $90 \%$. The materials and mobile layout of application consecutively scored $86.67 \%$ and 93.33\% which classified as "Good". The overall response from the teachers is positive which is to support the mobile learning application to be used in the teaching-learning process.

The highest percentage is for the quiz given after to do projects; it is stated that the exam can enhance students' comprehension of materials. One science teacher said that,

Table 2. The result of science teachers' and students ' responses to Unity.

\begin{tabular}{|c|c|c|c|c|c|}
\hline \multirow{3}{*}{$\begin{array}{l}\text { Category } \\
\text { Mobile } \\
\text { Connectivity }\end{array}$} & \multirow{2}{*}{$\begin{array}{l}\text { Statement } \\
\text { The application was a convenient and } \\
\text { sufficient time to consume. }\end{array}$} & \multicolumn{2}{|c|}{ Teacher score } & \multicolumn{2}{|c|}{ Student Score } \\
\hline & & \multirow[t]{3}{*}{86.6} & \multirow[t]{3}{*}{ Very Good } & 88.6 & Very Good \\
\hline & Easy to connect. & & & & \\
\hline & The materials are accessible. & & & & \\
\hline Materials & Materials are understandable & 93.3 & Very Good & 86.2 & Very Good \\
\hline Projects & $\begin{array}{l}\text { Projects are attractive, challenging and } \\
\text { improve the understanding }\end{array}$ & 93.3 & Very Good & 94.2 & Very Good \\
\hline Quiz & $\begin{array}{l}\text { The question in the exam can enhance } \\
\text { the comprehension }\end{array}$ & 86.6 . & Very Good & 95.6 & Very Good \\
\hline \multirow{3}{*}{$\begin{array}{l}\text { Mobile } \\
\text { Layout }\end{array}$} & The appearance is attractive. & \multirow[t]{3}{*}{93.3} & \multirow[t]{3}{*}{ Very Good } & 90.3 & Very Good \\
\hline & All text is seen and readable. & & & & \\
\hline & $\begin{array}{l}\text { All media are supported the material } \\
\text { comprehension. }\end{array}$ & & & & \\
\hline \multirow{2}{*}{$\begin{array}{l}\text { Personalized } \\
\text { Learning } \\
\text { Experience }\end{array}$} & $\begin{array}{l}\text { Mobile learning application is such a } \\
\text { meaningful learning }\end{array}$ & \multirow[t]{2}{*}{90} & \multirow[t]{2}{*}{ Very Good } & 100 & Very Good \\
\hline & $\begin{array}{l}\text { Gives advantages to create personalized } \\
\text { learning }\end{array}$ & & & & \\
\hline
\end{tabular}

"Hopefully it can continue to grow so that it can be mass-produced and useful for schools in Indonesia and abroad. Hopefully, this application can continue to be developed and can be made again in other physical matter."

The application generally helps students to give them more meaningful learning. One student stated that,

" This application is beneficial for learning because this application is very easy to get and also the problems can also increase the understanding of students. "

Mobile learning aims to help a teacher to give review and feedback to the students; it supports teachers to create design challenges related to school learning goals and in creating learning activities related to the steps of the design process and the level of design thinking of 
the students. Based on the questionnaire's result of science teachers' respond to this mobile learning application, the evaluation gain score of $90.55 \%$ within $100 \%$ range. This is categorized as a "very good" evaluation. Science teachers emphasize material aspects to be added and further elaborated. Quizzes are the most significant aspect that is important in this mobile application because as a science teacher review, quizzes can help students understand more about the topics of the earth layer that are interactively packaged. Interactive multimedia presented in this application is intended to make student learning activities in the school more enjoyable.

Mobile technology can have a positive impact if it designs, implements, and develops well to catch up with the 21 st century where the digital era is needed in the educational environment to make it available anywhere, anytime, for anyone, and affordable costs [9]. Students find this exciting learning application and help them build their understanding of the concept of the earth layer and its characteristics. Especially in the aspect of learning experience that has the highest score of all aspects with $100 \%$, students learn how this mobile learning application can simplify their understanding and help them to understand topics through projects. The science teachers noted that this mobile learning application creates a better-personalized learning experience for students; the evaluation shows $83.3 \%$ out of $100 \%$ that categorized as "very good."

Aside from what the experts had been evaluated, science's teacher responses and Junior High School students' responses, the prospect of this mobile learning application is generally welcomed. They gave positive evaluations towards this android mobile application as it is seen in their answer to the rubric and questionnaire evaluation. Students usually responses that mobile learning can make their study easier especially outside the class learning. Mobile learning is one of the frameworks in achieving maximize students' learning by easy devices and applications that can be identified at a right time, the right place to promote digitally-rick curricula that suitable for all education [10]. The accessibility and easiness of android mobile application can be taken as the strength despite the weakness also still present such as the connectivity and the revision of the material. According to the result and analysis of experts, science teachers, and Junior High School students toward this mobile learning application, it is evidenced that the android mobile app can gain their interest in learning the earth layer and make them willing to use it in science class. Therefore, the real implementation of this android mobile application as an enriching source besides the main textbook will bring some advantages to the learning process. The use of M-learning declares various chances to engage a set of knowledge widely, context construction beyond the formal educational set up [11]. Therefore, the implementation of this mobile learning application in the future is predicted to facilitate the teaching-learning process.

\section{Conclusion}

According to all evaluations conducted by experts, science teachers, and Junior High School students, this android mobile learning application, 'Unity' has received positive responses. All features proposed in the mobile learning application are helpful since they are perceived as useful and frequently used by students. For future work, the upgrade version of this application has to build with includes precious materials and a better flow of learning delivery. 


\section{References}

[1] Niess, M.L.: Preparing teachers to teach science and mathematics with technology: Developing a technology pedagogical content knowledge. Teaching and teacher education, Vol. 21(5), pp. 509-523 (2005)

[2] Rosenthal, I. G.: New teachers and technology: Are they prepared? (Technology information). Technology and Learning, Vol. 19(8), pp. 1-2 (1999)

[3] Islam, R., Islam, R. and Mazumder, T.: Mobile application and its global impact. International Journal of Engineering \& Technology (IJEST), Vol. 10(6), pp. $72-78$ (2010)

[4] Liu, C.C. and Kao, L.C.: Do handheld devices facilitate face-to-face collaboration? Handheld devices with large shared display groupware to facilitate group interactions. Journal of Computer Assisted Learning, Vol. 23 , pp. 285-299 (2007)

[5] Hoppe, H.U., Joiner R., Milrad M. and Sharples, M.: Wireless and Mobile Technologies in Education, Journal of Computer Assisted Learning, Vol. 19 (3), pp 255-261 (2003)

[6] Jones, S.: The Internet goes to college: how students are living in the future with today_s technology. Pew Internet and American Life Project, Sept. (2004)

[7] Cairncross, S. and Mannion, M.: Interactive multimedia and learning: Realizing the benefits. Innovations in education and teaching international, Vol. 38(2), pp. 156-164 (2001)

[8] Gravemeijer, K.: Developmental research as a research method.In Mathematics education as a research domain: A search for identity, Springer, Dordrecht. pp.277-295 (1998).

[9] Kiger, D., Herro, D. and Prunty, D.: Examining the Influence of a Mobile Learning Intervention on Third Grade Math Achievement. Journal of Research on Technology in Education, pp. 61-82 (2012)

[10] Robinson, R., and Reinhart, J.: Digital Thinking and Mobile Teaching. Communicating, Collaborating and Constructing in an Access Age (2014)

[11] Dyson, L., Andrew, T., Smyth, R. and Wallace, R.: Towards a Framework for Ethical Mobile Learning, pp. 405-406 (2013) 